\title{
Connecting instructional and cognitive aspects of an LE: A study of the global seminar project
}

\author{
Tamara Savelyeva
}

Received: 9 October 2009/Accepted: 28 May 2011/Published online: 26 April 2012

(C) The Author(s) 2012. This article is published with open access at Springerlink.com

\begin{abstract}
My research problem is based on the lack of unifying conceptual cohesion between the discourses concerning cognitive and instructional aspects of learning environments (LE). I contrast that lack with practical developments of LE studies connected at the level of practical implementation and evaluation. Next, I briefly review the LE boundaries, which are established within cognitive and instructional domains of LE research. This study aims to bring the aforementioned discourses together via reconsidering and clarifying LE conceptual understandings. Using the case of a global seminar project (GSP), my goal is to define an LE as a conceptual phenomenon and a practical model with the two objectives of determining the GSP's components that establish the course in a context of higher education; and the GSP's specific contributions to deep learning. Within a qualitative research framework, I used three forms of data collection: 20 open-ended interviews of the GSP instructors; 11 direct observations of the GSP classroom; and the GSP's written documents and artifacts. Noting the contextual significance of the suggested LE framework that resulted from this study, I propose a definition of an LE as a conceptual phenomenon and educational model. Here, I introduce the key understandings of an LE and outline its significance based on a broader analysis of the results. I conclude with an interpretation of the results and potential limitations of my approach.
\end{abstract}

Keywords Educational concept · Educational model · Educational psychology and instruction · Higher education · International project · Learning environment . Qualitative research methods

\section{Introduction and background}

During the last decade, educational research has revealed numerous important insights concerning instructional and cognitive aspects of learning environments (LE). By shedding

T. Savelyeva $(\bowtie)$

Faculty of Education, The University of Hong Kong, 110 Hui Oi Chow Science Building, Pok Fu Lam Rd., Hong Kong, China

e-mail: tsavelyeva@gmail.com 
light on the processes of constructing and implementing LE, promising perspectives have come from two major disciplinary domains: educational psychology and instruction.

This study was based on the assumption that the discourses concerning instructional and cognitive aspects of LE intersect in practice, but not in theory. The obvious connections between the domains can be identified at the practical level during course/project implementation and evaluation. A disconnection can be found in the key concepts that underline the practices within each LE domain.

At the practical implementation level, the LE domains of educational psychology and instruction are connected in the area of goal setting and are linked through a series of projects and educational case studies. The goal to advance students' learning provides focus to all the LE studies that investigate the implications of different factors that enhance the quality of teaching and learning. The practical interlinking between educational psychology and instruction provides evidence of success from real projects and cases. The various instances of international cross-disciplinary studies can be exemplified by articles of Coutinho and Neuman (2008), Sarfo and Elen (2007) and Fraser and Lee (2009). Coutinho and Neuman used a structural equation model to test an original three-component cognitive framework, aiming to explain variations in student performance in the United States. Sarfo and Elen (2007) advanced the use of a 4C/ID model (van Merriënbour 1997) for addressing complexity of instructional design in technical education in Ghana. The 4C/ ID model stands for a four-component instructional design model involving (1) learning tasks, (2) supportive information, (3) procedural information and (4) part-task practice. Fraser and Lee (2009) used the Science Learning Inventory Scale to evaluate the learning environment in Korean science classrooms. Performed within the boundaries of different domains of LE research, these empirical studies are just a few of many that show the practical connections between educational psychology and instruction.

This link between cognitive and instructional aspects of LE research can also be found beyond the classroom through the co-responsive domain of educational evaluation. Educational evaluation simultaneously responds to the needs of the instructional and cognitive domains to measure assess and evaluate the degree of achieving the goal of advancing students' learning. It takes the role of a sealing factor that joins parallel and dispersed theoretical schools through the application of measurement instruments. Important work by Rudolf Moos, Herbert Walberg and John Biggs led to the development of comprehensive and reliable LE evaluation scales. Moos' work in numerous human environments led to the development of the Classroom Environment Scale (Moos and Trickett 1974; Trickett and Moos 1973). Assessing the Harvard Project Physics project (Walberg and Anderson 1968) led to the Learning Environment Inventory that measures student perceptions of the social climate in classrooms (Fraser et al. 1982). Biggs (1987a, b) created the Study Process Questionnaire (SPQ) to investigate factors contributing a constructive alignment of teaching and learning practices in a classroom. It is used to describe the level of increasing complexity in learners' understanding of a subject. Although all LE studies retain a certain level of theorising, the development of a cohesive concept that interlinks educational psychology and instruction in LE research remains a challenge. The variety of proposed conceptual frameworks related to learning and instructional theories encourages connections to support common educational goals. However, these theories do not interlink and, in some cases, exclude each other. For instance, the conceptual variations within educational psychology - in our time_-sprout mostly from the constructivist theory of learning. In instructional design, the usefulness of the constructivist approach remains debatable, mostly because of its lack of capability within the system approach and a linear format of instructional strategies. 
Disconnection in theory, or absence of a discourse that offers conceptual cohesion to LE research, might be viewed as a comfortable co-existence of educational psychology and instruction in practice. However, there is a need for a unifying theory to "describe the reality ... and contain a comprehensive set of propositions about what its subject looks like and how it works" (Warries 1987, p. 106). Failure to appear in theory should be a concern and it should serve as a starting point for an innovative and reflective study on the conceptual and practical boundaries and interlinkages of the different aspects of LE research. In the pursuit of such a reflection, I conducted a study to provide a base for the desirable re-consideration and clarification of LE conceptual frameworks. Serving as a qualitative examination of a real-life case, this study should be viewed as an attempt to link together the cognitive and instructional aspects of an LE.

To achieve my purpose and define an LE as a conceptual phenomenon and a practical model, it is important to understand that the meaning of an LE as a term varies across educational domains. Before discussing the study, I introduce its broader context and discuss boundaries of an LE to highlight the attributes of the study and facilitate its critical apprehension.

\section{Boundaries of an LE}

Consisting of two parts, learning and environment, the term LE is dual in its nature. I distinguish two major lines of LE inquiry that emerge from this duality. Studies associated with learning are focused on different types of learning and specific learning mechanisms; studies associated with environment are focused on factors that help facilitate learning. The terminological duality perfectly reflects the separation between LE studies along cognitive and instructional lines of research.

In educational psychology, where learning is approached as a process of active cognitive undertaking, LE studies "tell us about the cognitive functioning during the learning process and desired changes in knowledge representation" (Warries 1987, p. 107) Unfortunately, as Warries points out, "that knowledge is rarely in the form which can be used by instructional ... theorists to alter the phenomena and to produce output of the instructional system" (p. 107). This creates a controversy about the meaning and the boundaries of an LE. The terminological mixture resulting from this controversy produces terms, such as powerful learning environment (van Merriënbour and Paas 2003), learnercentred environment (Twigg 2001), innovative LE (Brown and Campione 1996) and teaching-LE (Entwistle et al. 2003).

In educational instruction, where one attempts to specify different instructional activities for learning events and in different subjects, LE studies have shown the relation between different factors influencing learning processes. This research approach also produces terminological variations. For example, the term e-learning environment, which is used to tell us how to use technology in instruction, has many variations, including information and communication technology (ICT)-based integrated LE, technology reach environments, multimedia LE, complex computerised environments, telematics and distributed LE. Also, within the domain of educational instruction, learning factors are mostly associated with the structural and interactive components of an LE model. This suggests the best format for usable instructional models. In contrast, studies that originates within the domain of educational psychology view LE factors in relation to the social and contentoriented structure of an LE. 
Altogether, LE studies comprise a significant dimension in the research literature that allows one to create a broad vision of different LE aspects. However, studies that unify the domains of educational psychology and instruction are fairly rare and scattered across educational disciplines. Studies dedicated exclusively to the goal of identifying the boundaries of LE are rather exceptional and difficult to categorise on the grounds of common continuities. Two examples of such exceptional work include Minstrell and Stimpson (1996) and van Merriënbour and Paas (2003).

Minstrell and Stimpson undertook a detailed analysis of curricula and pedagogical aspects of an LE. The central question that they posed involved "what it means to create an environment that fosters student reconstruction of understanding and reasoning" (p. 178). By investigating an LE in a science classroom, they distinguished the following descriptive features of a LE: it is critical and supportive; it provides room for verbal interaction and questioning; and it involves an assessment, which is based on real-world situations and problems.

Van Merriënbour and Paas, on the other hand, provided an exposure to the structure of a learning environment built in alignment with human cognitive architecture. They focused on the instructional methods that optimise a cognitive load for the 'blueprint components' of a LE, which include a world of learning, world of knowledge, and world of work. Merriënbour and Paas argued that LE "are defined as environments aimed at complex learning, deep conceptual understanding, and metacognitive skills" (p. 17). Using this definition, they illustrated an LE design model that fulfills three conditions: "take[s] an eclectic view on learning... distinguish[es] blueprint components and ... methods aimed at complex learning; and align[s] [those] methods with human cognitive architecture" (p. 17).

Other work that attempts to interlink the educational domains and provide the characteristics of an LE includes Vosniadou (1996). Vosniadou identified the following characteristics of LEs: (1) LEs support active learning and guide students towards acquisition of self-regulated processes; (2) learners actively construct their own knowledge and skills within LEs; (c) tasks within LEs are relevant and meaningful to students' experiences and are contextualised with the real world; (d) LEs are designed with respect to the students' individual differences; and (e) LEs deliberately use social context and collaboration in learning.

The variety of definitions of an LE and their lack of connection with an educational theory across the domains created some discrepancies among researchers in the field of educational and cognitive psychology. Laurillard (2001), of the Open University in UK, questioned the idea of applying instructional design approaches within a framework of educational psychology and cognitive learning:

There are no data on the theoretical development of this approach that derives from students learning in an instructional context. The theory can be used to generate teaching which is then evaluated, but this does not test the approach, only its instantiation in that piece of instruction (p. 65).

On the contrary, Warries (1987) of the University of Twente in Netherlands pointed out that most educational theory concerning adult student instruction and training is developed from educational practices and past experiences of educators that serve as bases for further theoretical developments:

Instruction had to start as a set of techniques or strategies. Systematic description and theorizing came later. After all, Socrates practiced inquiry teaching without having to develop a counterpart of Collins' theory and generations of teachers gave examples 
and general statements long before Merrill described his primary presentation forms (p. 107).

Being aware of the gap between theory and practice, I undertook this study that aimed to link the cognitive and instructional LE discourses together via defining an LE as a conceptual phenomenon and a practical model.

\section{Overview of the study}

As the complexity of issues related to LE requires guidance from multiple theories at different levels of analysis, my initial research plan was guided by constructivist theory (Piaget 1962; Vygotsky 1979/1925) and Biggs' (2003) deep learning perspective. The integration of elements from these two frameworks provided a broad perspective from which to simultaneously examine the nature of an LE and its contributions to learning.

For this research, I studied the case of a global seminar project (GSP) as an example of an LE. I stated the goal to define a learning environment as a conceptual phenomenon and a practical model in two objectives. First, I aimed to determine the GSP's components that establish the course in a context of higher education. Second, I aimed to determine the GSP's specific contributions to deep learning. Based on these research objectives, I articulated the following research questions to guide my study: (1) What are some of the characteristics of the course's LE? and (2) In what ways does GSP contribute to deep learning?

\section{The research case: Global Seminar Project}

The GSP see http://www.globalseminar.org) is a collaborative program that offers an academic credit course on environment and sustainability to undergraduate and graduate students. This course was launched in 1999 at Cornell University, USA. At the beginning, the GSP connected seven agricultural colleges from around the world by offering virtual lectures on a central theme of sustainability. Over a period of 2 years, the participating university faculty developed a comprehensive curriculum and synchronised its formats to suit different kinds of international institutions. Today, the GSP course is simultaneously taught internationally in 40 universities, community colleges and high schools.

The GSP is notable for its distinct course structure. The participating universities are grouped into learning clusters of a maximum of six institutions. A faculty volunteer coordinates each learning cluster from one of the institutions. The staff work together to simultaneously offer this course at their respective institutions. They use the same case studies and engage students in cross-institutional work teams called international student groups. Cluster management is facilitated through periodic e-mail exchange and videoconferences. The GSP's staffs meet at a bi-annual conference to plan the course, which is usually offered in the spring semester.

The course consists of 3-week learning cycles. During each learning cycle, GSP students address different aspects of sustainability, discuss a case study and create their solution to a given problem. The examples of case studies used in this course include, but are not limited to population dynamics, global warming, biodiversity and geneticallymodified organisms. At the end of each learning cycle, students present their results at a 
student-led videoconference, when they negotiate a group consensus and finalise their solutions as a group.

I selected the GSP for the study because of its innovative nature. The GSP integrates new educational methods, such as decision case studies and international student groups, and it applies advanced technologies to promote interaction. In this sense, GSP advocates educational change from traditional pedagogy to constructive learning and represents both deep and constructive approaches to teaching and learning. This course also allowed me to address the research problem of defining LE in higher education within different cultural contexts.

\section{Method}

Research design

In this study, I applied a qualitative design as the methodological framework for constructing a rich, detailed and comprehensive description of an LE and for exploring its contributions to deep learning. I used a purposeful intensive-sampling method and identified GSP participants, settings and activities, which were most suited for providing detailed information about the project. I used the following forms of data collection:

1. Twenty in-depth, open-ended and face-to-face interviews with GSP faculty (cluster coordinators and teaching instructors) about their experiences, beliefs and knowledge concerning the nature of their LE. The interviewees came from 12 US States, Puerto Rico, Mexico, Costa Rica, Italy, Australia, Sweden, Honduras, South Africa, Germany, Austria and Denmark.

2. Eleven direct observations of the GSP classroom that incorporated both descriptive and reflective notes about the participants' activities and actions during class sessions, different interaction patterns among the participants, and class arrangements and structure.

3. Written GSP documents, narratives and artifacts, which included conference papers and materials available at the project's website, course syllabi, promotion papers, homework assignment and feedback sheets, class hand-outs and other documents created and presented by the participants during the semester.

Instrument and data collection

The interview instrument consisted of open-ended questions, which I created in relation to the LE data available in the literature. As new themes emerged during data collection, the open-ended method of interviewing allowed greater flexibility for expanding initial interview categories. To develop the observation instrument, I modified a classic observation template (Creswell 2003) by including specific items that captured the instances of deep learning. These observation items reflected the information about deep learning found in the literature (Biggs 1987a, b; Prosser and Trigwell 1998; Trigwell and Prosser 1996) and also the data derived from the interviews. The observation items from the literature described teaching and learning strategies in the classroom. The observation items derived from the interviews included two categories: types of interaction and participation in the classroom. For the GSP document analysis, I adopted Miles and Huberman's (1994) document summary form. I conducted the interviews during the GSP bi-annual meeting in 
Arlington, VA (USA) in July 2005. I performed the observations and document analysis during the 2007 spring semester at Virginia Polytechnic Institute and State University (USA).

Data analysis

The data analysis was ongoing as I continuously read and reorganised the data throughout the research and documented my procedures. First, I analysed the data collected during the interview stage of this research. I manually transcribed and verified each interview. Next, I downloaded the transcripts to the ATLAS.ti software. For the interview analysis, I used the open-coding (Corbin and Strauss 2007) feature of the ATLAS.ti software for reading the transcripts and coding passages in the margins.

Second, I analysed the GSP's observation materials and the GSP documents for an appearance of common themes and topics related to the research questions. I applied a coding-recoding strategy (Anfara et al. 2002) to my analysis and generated the coding scheme after several weeks of open coding. The coding-recoding strategy involves coding, reviewing, and re-coding each transcript in accordance with the final coding schema. Table 1 presents the final coding categories, which I generated during the analysis of the interview and observation data. To ensure participant confidentiality, I obtained institutional review board (IRB) approval through the standard Virginia Tech IRB procedure at each stage of this research project.

Data quality procedures

I applied four forms of data quality indicators: credibility, transferability, dependability and confirmability (Guba and Lincoln 1994).

Credibility involves developing believable results from the participant's perspective. To satisfy the criteria for credibility, I (1) provided insightful descriptions that offered the meanings and essences of the participants' experiences, as well as demonstrated an

Table 1 Descriptive codes used during the interview and observation phases (Savelyeva 2009)

\begin{tabular}{|c|c|c|}
\hline Phase of research & Codes used & Description of codes \\
\hline \multirow[t]{5}{*}{ Interview } & P-CS/ALM & $\begin{array}{l}\text { Perceptions about course structure and } \\
\text { academic leadership/management }\end{array}$ \\
\hline & P-SI & Perceptions about stakeholder involvement \\
\hline & P-IS & Perceptions about institutional support \\
\hline & $\mathrm{P}-\mathrm{CC}$ & Perceptions about course conducive content \\
\hline & P-TL & Perceptions about teaching and learning practices \\
\hline \multirow[t]{8}{*}{ Direct observation } & $\mathrm{I}-\mathrm{ST}$ & Interactions between students and teachers (instructors) \\
\hline & $\mathrm{I}-\mathrm{II}$ & Interactions between instructors \\
\hline & I-SS & Interaction among students \\
\hline & P-SE & Type of participation: student elaboration \\
\hline & P-SI & Type of participation: student improvisation \\
\hline & $\mathrm{P}-\mathrm{CI}$ & Type of participation: prepared and immediate conversation ideas \\
\hline & S-EI & Teaching strategies employed by instructors \\
\hline & S-ES & Learning strategies employed by students \\
\hline
\end{tabular}


adherence to bracketing, and (2) triangulated the various sources of information gathered (interview, observation, and documents and artifacts). In qualitative terms, bracketing implies a researcher's ability to separate his/her personal knowledge from his/her life experiences.

Transferability is the degree of generalizability of the results to other settings. In order to maintain transferability, I (1) provided a thorough description of the research context and assumptions central to the study and (2) used a purposeful sampling method.

Dependability is the degree to which the researcher accounts for changes that occur and how those changes influence the study. To ensure dependability, I (1) documented and provided an explicit explanation of any change in the study and their impact on the study, (2) triangulated the methods of the study (interview, observation and documents and artifacts) and (3) applied coding-recoding strategy to data analysis.

Confirmability is the extent to which others can confirm the results. To accomplish confirmability of the results, I (1) documented procedures and re-examined the data throughout the study and (2) used the ongoing types of data-gathering and data-analysis methods.

\section{Results and interpretations}

I derived emergent themes from the interview analysis and developed them using the constant comparative method (Lincoln and Guba 1985). The constant comparative method involves four stages: comparing incidents applicable to each category; integrating categories and their properties; delimiting the theory; and writing the theory. The interview analyses revealed that the course LE included five characteristics: course structure and academic leadership/management; stakeholder involvement; institutional support; courseconducive content; and teaching and learning practices. These items collectively comprised the conditions required for bringing about the unique GSP learning environment (Fig. 1).

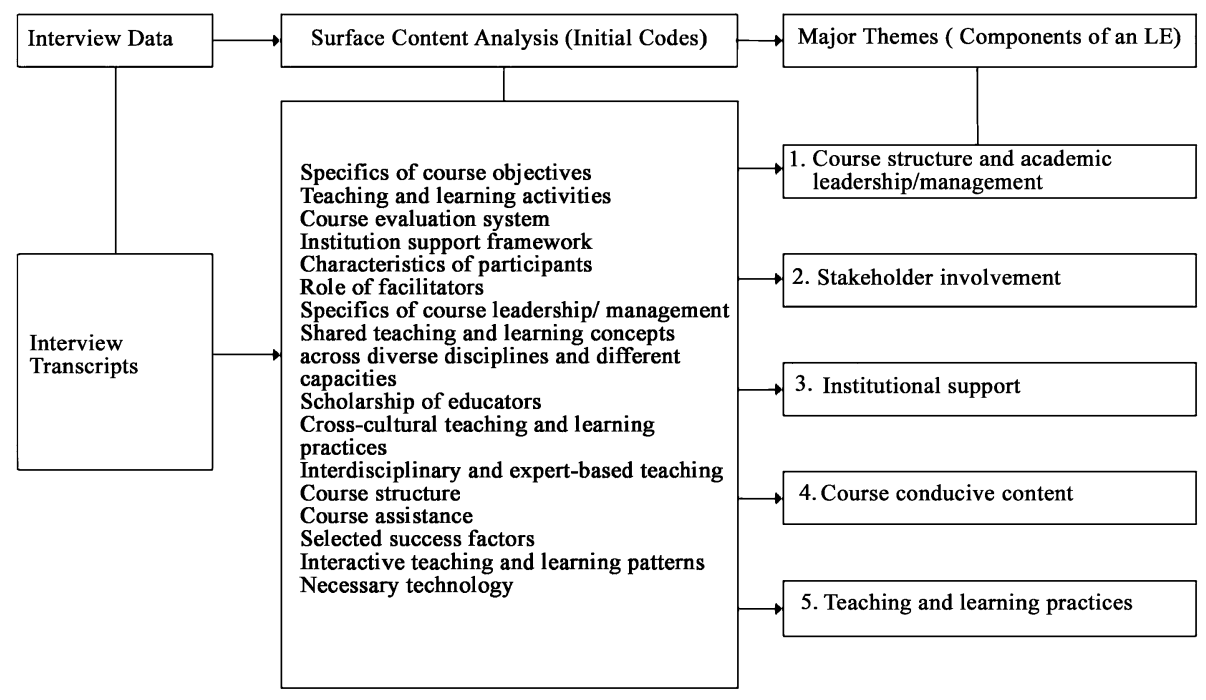

Fig. 1 Components of an LE as they appeared in the GSP (Savelyeva 2009) 
The findings of deep learning that resulted from the GSP's direct observation can be grouped in three major categories: observed development of students' generic metacompetencies; identified components of instructors' teaching quality; and recognised value of the relationships among course participants (Fig. 2).

I developed two definitions of an LE as a conceptual phenomenon and an educational model, using the research parameters defined by the theoretical frameworks, the initial research questions and the reported results. Then, I developed interpretations of the findings to ensure clear apprehension of the proposed LE framework.

\section{LE is a conceptual phenomenon}

I define a conceptual phenomenon of an LE as follows: LE is a specific property of an educational structure that occurs when teachers and students are engaged in innovative experiences with the purpose of acquiring understanding of complex global-scale issues by means of cross-cultural interactions and on the basis of mutual learning. Generated from the adaptive and incremental analysis of the results, my definitive vision of an LE includes several conceptual properties that represent the following descriptive characteristics of an LE:

- LE is a specific property of an education structure. It is not a physical space.

- LE occurs when teachers and students are engaged in innovative experiences that give the participants a sense of discovery, excitement and novelty.

- The LE activities are built around the purpose of acquiring understandings of complex, large-scale issues that require non-linear solutions.

- The participants form their understandings and reasoning by means of dynamic crosscultural communication and interaction. Diversity and dynamic communication facilitate the LE phenomenon.

- LE is built on the basis of mutual learning. Both teachers and students undergo a 'learning curve'.

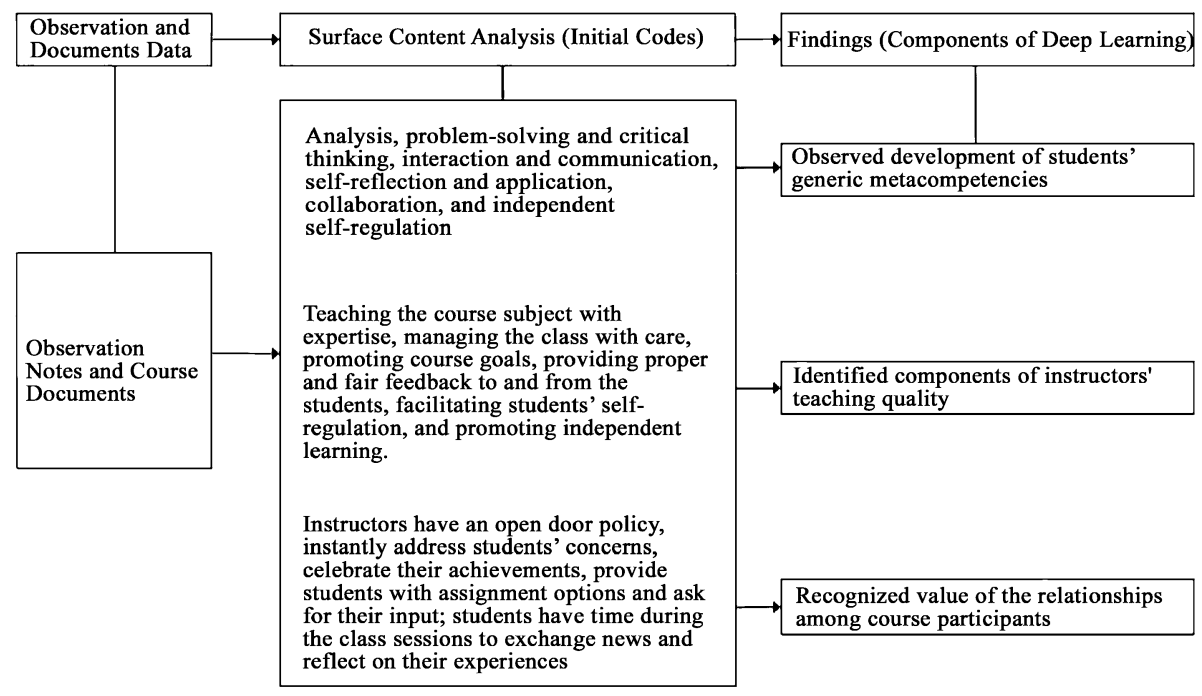

Fig. 2 Observed evidences of deep learning 
I developed the following interpretations of this conceptual phenomenon:

- LE is socially and culturally situated The LE is a dynamic concept, as all of its attributes appear to be socially and culturally situated. In this sense, an LE is closely connected with Wertsch's (1991) sociocultural approach to mediated action, which addresses the issues of individual learning as a complex endeavour shaped by institutional, cultural and historical factors. Wertsch used the social constructivism of the Vygotskian theory, arguing that understanding of learning phenomena is rooted in the analysis of interactions among its multiple dimensions:

The ideal unit of analysis preserves in a microcosm as many dimensions of the general phenomenon under consideration as possible, thereby allowing one to move from one dimension to another without losing sight of how they fit together into a more complex whole (Wertsch 1991, p. 121).

Using Wertsch's idea to analyse an LE as a conceptual phenomenon, I argue that, to better understand an LE and its appearances in higher education, all its aspects (see Fig. 1) should be viewed together as educational constructs employed in social, cultural and institutional situations.

- Mutual learning is the guiding principle that preserves LE's aspects together In the context of this research, the culture of mutual learning implies a learning curve for students and instructors who built their understandings of the project by (1) challenging each other's fundamental assumptions about the course and (2) constructing individual and group meanings of their teaching and learning practices. The understanding of the culture of mutual learning as it appeared in this study parallels those found in the literature (Nielsen et al. 2003; Posch and Steiner 2006). It is important to note that, much in line with Posch and Steiner's findings, the culture of mutual learning, as it emerged in this research, has established grounds for innovations among the course participants.

- The LE's conceptual parameters reaffirm the perceptual elements of LE presented in previous studies The findings of the study connect my interpretation of an LE as a conceptual model with the existing educational research. In the proposed definition, I acknowledge Minstrell and Stimpson's (1996) and van Merriënbour and Paas' (2003) parameters of LE (see the section "Boundaries of an LE" of this paper). Seen in this way, the LE's features can be viewed as the means by which the instructional and cognitive frameworks can jointly establish themselves effectively within practice.

- LE promotes the ideas of interdisciplinarity and non-linear solutions Interdisciplinary, in Stembler's (1991) words, is "a complex endeavor that seeks to explicate relationships, processes, values, and context using the diversity and unity possible only through collaborative approaches" (p. 5). It helps a group to create greater understanding of a subject. From this perspective, an LE promotes all of the elements of Stembler's interdisciplinarity framework, such as: intellectual hospitality; ability to share and learn another discipline's cognitive map (Petrie 1976); bringing personal biography to the group; and recognising differences. A cognitive map consists of basic concepts, modes of inquiry, what counts as a problem, representation techniques, standards of proof, types of explanation, and general ideas of what constitutes the discipline. 
LE is an educational model

I developed the following definition of an LE educational model: applied to an educational practice, an LE can be viewed as a constructive and participatory educational model that provides possibilities for transforming higher education practices that promote deep learning.

While examining the aspects of the GSP's learning environment within the frameworks of constructivist theory and a deep learning concept, I grew to appreciate each area of its educational model as constructive and participatory in style, structure, and management and content. It is the LE's constructive and participatory attributes that make its processes and practices truly transformative to education. I developed the following interpretations of the LE model:

- LE promotes a constructivist perspective for teaching and learning The application of a constructivist perspective allows one to view an LE as the result of participants' manipulation of their own subjectivities and cultural perspectives that help to create new meanings through dialogue and to initiate transformations in learning and understanding. LE is a result of the dialectical interaction between learners, an activity in which they are engaged, and the environment in which this interaction takes place. This understanding of an LE reflects the Vygotskian view on learners' development in which the "social dimension of consciousness is primary in time and in fact. The individual dimension of consciousness is derivative and secondary" (Vygotsky 1979/ 1925, p. 30). Following this idea, I argue that an LE emphasises cognitive and social development as practices achieved both through the work of an individual consciousness and through collective cultural mediation.

- LE generates deep learning Both personal and situational factors of the Biggs' (2003) model emerged among the research findings. In alignment with Biggs' concept, the GSP participants mastered and critiqued their ways of knowing by creating new meanings with respect to their personal lives. They culturally constructed understandings of their own reality at the deepest level of the processing of knowledge.

- LE involves constructive and participatory approaches to teaching and learning This understanding opens an analytical avenue for the exploration of teaching and learning that, in the words of O'Loughlin (1992), possibly "leads to genuine ownership of ideas and possibilities for transformation" (p. 809). Despite a well-supported trend in educational research that questions the value of the constructivist framework for studies on educational change (Prosser and Twiggel 1997), the results of this study let one recognise its ability to produce deep learning in a constructive and participatory way.

- LE model is transformative The constructive and participatory components of an LE make its processes and practices truly transformative to education (Savelyeva and McKenna 2011). This understanding promotes Sterling's (2001) ideas of education for change and education in change. Advancing education for change, an LE initiates change in the person and a group of the GSP participants, who further promote change in a society. LE also promotes education in change, as it leads to change in policies, theories and educational practices that facilitate education for change.

- Educational quality of an LE depends on intrinsic values of an individual teacher LE creates challenging pedagogical situations. By overcoming these challenges, the instructors gain a sense of their professional growth. Their teaching quality also improves. Approached this way, the LE's overall quality can be best described using 
Astin's (1980) quality categories, such as capacity for change and constant improvement.

- LE elements should be perceived simultaneously While examining the LE's structure, I viewed all of its elements in close relation to each other and avoided the linear systemdesigned approach of input, process and output (Savelyeva and McKenna 2011). LE elements sustain each other and are not independent. I argue that the use of a non-linear approach to LE analysis is most feasible, as it provides the most complete image of an LE. This supports Trigwell and Prosser's (1997) assumption that, in educational modeling, the experiences of a researcher and participants are always affected by a 'temporality' factor. Applied to this research, the notion of temporality highlights the complex relationships among LE elements. In the context of this research, the temporality factor implies that all parts of an educational model are viewed together and are presented and experienced simultaneously by participants at the moment of inquiry.

- LE is an interactive system The relationship between LE elements should be perceived as an interactive system. As argued by Meyer (2000), this approach might imply more complex bonds among components of an educational model. I also maintain that the social connections established among participants of the GSP course affect the interaction between the components of an LE model. For example, close and trusting relationships among participating students and instructors established their positive perceptions about the course and its challenging nature. I argue that trusting relationships sustained an LE as an interactive system. I am inclined to believe that strong social bounds also affected participants' learning. As noted by Entwistle (1998), positive perceptions of the participants, not the educational method, have the strongest effect on individual learning.

\section{Limitations}

The proposed definitions of an LE as a conceptual phenomenon and practical model reflect the descriptive nature of the words 'concept' and 'model'. This research was not an evaluation of a project, but rather a descriptive study in which an LE was viewed through the lens of educators' perceptions. Given the purpose of my study, the size of the project under investigation, and the international composition of the participants, evaluation were not feasible.

As with any descriptive study, I acknowledge the limitations of the analysis and the results obtained. The first concern is that my approach identified evidences of deep learning based on the data observed by a single researcher and voluntarily reported by the instructors during interviews, and not by the students themselves. Such a selection bias could lead to overestimating the instances of deep learning and 'high-order' thinking among students. At the same time, the selection bias would have detected any instance of a 'low-order' thinking which, in fact, did not occur. Thus, in the study, I am reasonably certain that any selection bias did not affect the results. The observation results are based on the records of students' discussions and their interactions in a classroom. The small size of the observed student group allowed accurate recording and direct quotation from students' interactive conversations, videoconferences and guided discussions.

The results of interview analysis were grouped together into five descriptive categories. The hope was that, by clustering components, I could capture the particularities of LE that 
made it successful in different cultures without creating a separate category. A unique part of the GSP is that it embraces cross-cultural and inter-disciplinary interactions in every aspect of the course. This helps to sustain the project around the world. The findings are inconsistent with the notion that LE structure needs its own cultural category. The results of the study conducted by Entwistle et al. (1996) support this perspective by noting the effect of the specific institutional and disciplinary context on every part of teaching-LEs.

A third possible limitation is that an LE is too complex and a composite of many interacting meanings of learning within domains of educational psychology and instruction. The proposed framework seems to be lacking in prescriptive suggestions for practitioners, but it is not. The non-linear approach to understanding an LE reflects reality and proposes a comprehensive set of activities to be interpreted and tested in the classroom. Despite these limitations, the descriptive and conclusive findings generated in the study nurture a vision for unifying the LE's concept and model. I aspire to connect learning and instruction and serve my fellow researchers and practitioners in the long run.

\section{Conclusion}

In this study, I used the voices of international university staff to define a unique concept of an LE that unites its practical domains of educational psychology and instruction into a conceptual concept and model. My hope is that this new connecting framework and model will serve as a basis for future systematic investigations of LE because it cuts across multiple sections of cognitive and instructional domains.

The results reaffirm that LEs can be used as a transformative, participatory and constructive educational system; however, all of the components of this system should be viewed simultaneously and in close relation to each other. I indentified and clustered the LE components into the five primary categories of course structure and academic leadership/management, stakeholder involvement, institutional support, course conducive content, and teaching and learning practices. These groupings resulted from a merger of two separate educational domains and facilitated development of an LE as a conceptual phenomenon and an educational model, which I defined and interpreted in the study. The findings show that LEs have unique features and far-reaching understandings that reflect the complex connection between cognitive and instructional aspects of pedagogy.

Acknowledgments I would like to acknowledge the helpful feedback of the following colleagues in reading the earlier draft of this paper: Michael Barnes of the Duke University, USA; John Hillison, Jim McKenna and Daisy Stewart of the Virginia Tech University, USA.

Open Access This article is distributed under the terms of the Creative Commons Attribution License which permits any use, distribution, and reproduction in any medium, provided the original author(s) and the source are credited.

\section{References}

Anfara, V., Brown, K., \& Mangione, T. (2002). Qualitative analysis on stage: Making the research process more public. Educational Researcher, 31(7), 28-38.

Astin, A. (1980). When does college deserve to be called "high quality?". Current Issues in Higher Education: Proceedings of the American Association of Higher Education, USA, 1, 1-4.

Biggs, J. (1987a). Study process questionnaire manual and questionnaire. Melbourne, Australia: Australian Council for Educational Research. 
Biggs, J. (1987b). Study process questionnaire. Melbourne, Australia: Australian Council for Educational Research.

Biggs, J. (2003). Teaching for quality learning at university (2nd ed.). Berkshire, UK: The Society for Research into Higher Education and Open University.

Brown, A., \& Campione, J. (1996). Psychological theory and the design of innovative learning environments: On procedures, principles, and systems. In L. Schauble \& R. Glaser (Eds.), Innovations in learning: New environments for education (pp. 289-325). Mahwah, NJ, USA: Lawrence Erlbaum.

Corbin, J., \& Strauss, A. (2007). Basics of qualitative research: Grounded theory procedures and techniques (3rd ed.). Newbury Park, CA, USA: Sage.

Coutinho, S., \& Neuman, G. (2008). A model of metacognition, achievement goal orientation, learning style and self-efficacy. Learning Environment Research, 11, 131-151.

Creswell, J. (2003). Research design. Qualitative, quantitative and mixed approaches. Thousand Oaks, CA: Sage.

Entwistle, N. (1998). Improving teaching through research on student learning. In J. Forest (Ed.), University teaching: International perspectives (pp. 73-112). New York: Garland.

Entwistle, N., McCune, V., \& Hounsell, J. (2003). Investigating ways of enhancing university teachinglearning environments: Measuring students' approaches to studying and perception of teaching. In E. De Corte, L. Verschaffel, N. Entwistle, \& J. van Merriënbour (Eds.), Powerful learning environments: Unrevealing basic components and dimensions (pp. 89-109). Boston, MA, USA: Pergamon.

Fraser, B., \& Lee, S. (2009). Science laboratory classroom environments in Korean high schools. Learning Environment Research, 12, 67-84.

Fraser, B., Anderson, G., \& Walberg, H. (1982). Assessment for learning environments: Manual for learning environment inventory $(L E I)$ and my class inventory $(M C I)$. ERIC document reproduction service no. ED 223649. Retrieved September 22, 2009, from ERIC database.

Guba, E., \& Lincoln, Y. (1994). Competing paradigms in qualitative research. In N. Denzin \& Y. Lincoln (Eds.), Handbook of qualitative research (pp. 115-117). Thousand Oaks, CA: Sage.

Laurillard, D. (2001). Rethinking university teaching (2nd ed.). London: Routledge.

Lincoln, Y. S., \& Guba, E. G. (1985). Naturalistic inquiry. Newbury Park, CA, USA: Sage.

Meyer, J. (2000). The modeling of a "dissonant" study orchestrations in higher education. European Journal of Psychology of Education, 15(1), 5-18. ERIC document reproduction service no. ED 658234. Retrieved October 16, 2009, from ERIC database.

Miles, M., \& Huberman, M. (1994). Qualitative data analysis: An expanded sourcebook (2nd ed.). Thousand Oaks, CA, USA: Sage.

Minstrell, J., \& Stimpson, V. (1996). A classroom environment for learning: Guiding students' reconstruction of understanding and reasoning. In L. Schauble \& R. Glaser (Eds.), Innovations in learning: New environments for education (pp. 175-202). Mahwah, NJ, USA: Lawrence Erlbaum.

Moos, R. H., \& Trickett, E. J. (1974). Classroom environment scale manual. Palo Alto, CA, USA: Consulting Psychologists.

Nielsen, J., Dirckinck-Holmfeld, L., \& Danielsen, O. (2003). Dialogue design with mutual learning as guiding principle. International Journal of Human-Computer Interaction, 15(1), 21-40.

O’Loughlin, M. (1992). Rethinking science education: Beyond Piagetian constructivism toward a sociocultural model of teaching and learning. Journal of Research in Science Teaching, 29, 791-820. doi: 10.1002/tea.3660290805.

Petrie, H. (1976). Do you see what I see? The epistemology of interdisciplinary inquiry. Educational Researcher, 5, 9-15. doi:10.3102/0013189X005002009.

Piaget, J. (1962). Comments on Vygotsky's critical remarks concerning "the language and thought of the child, and judgment and reasoning in the child." Boston: MIT. Retrieved October 22, 2007, from http://www.marxists.org/archive/vygotsky/works/comment/piaget.htm.

Posch, A., \& Steiner, G. (2006). Integrating research and teaching on innovation for sustainable development. International Journal of Sustainability in Higher Education, 7(3), 276-292.

Prosser, K., \& Twiggel, M. (1997). Towards an understanding of individual acts of teaching and learning. Higher Education Research \& Development, 16, 241-252.

Prosser, M., \& Trigwell, K. (1998). Understanding learning and teaching: The experience in higher education. Milton Keynes: Open University.

Sarfo, F., \& Elen, J. (2007). Developing technical expertise in secondary technical schools: The effect of 4C/ID learning environments. Learning Environments Research, 10, 207-221.

Savelyeva, T. (2009). Global learning environment: Innovative concept and interactive model for changing academia and academics. Saarbrücken, Germany: VDM-Verlag.

Savelyeva, T., \& McKenna, J. (2011). Campus sustainability: Emerging curricula models in higher education. International Journal of Sustainability in Higher Education, 12(1), 55-66. doi:10.1108/146 76371111098302 . 
Stembler, M. (1991). Presidential address advancing the social sciences through the interdisciplinary enterprise. The Social Science Journal, 28(1), 1-14.

Sterling, S. (2001). Sustainable education: Re-visioning learning and change. Devon, UK: Green Books.

Trickett, E. J., \& Moos, R. H. (1973). Social environment of junior high and high school classrooms. Journal of Educational Psychology, 65, 93-102. doi:10.1037/h0034823.

Trigwell, K., \& Prosser, M. (1996). Congruence between intention and strategy in science teachers' approach to teaching. Higher Education, 32, 77-87.

Trigwell, K., \& Prosser, M. (1997). Towards an understanding of individual acts of teaching and learning. Higher Education Research and Development, 16, 241-252.

Twigg, C. (2001). Innovations in online learning: Moving beyond no significant difference. Retrieved October 12, 2007, from http://www.thencat.org/Monographs/Mono4.pdf.

van Merriënbour, J. (1997). Training complex cognitive skills: A four-component instructional design model for technical training. Englewood Cliffs, NJ, USA: Educational Technology.

van Merriënbour, J., \& Paas, F. (2003). Powerful learning and the many faces of instructional design: Toward the framework for the design of powerful learning environments. In E. De Corte, L. Verschaffel, N. Entwistle, \& J. van Merriënbour (Eds.), Powerful learning environments: Unrevealing basic components and dimensions (pp. 3-20). Boston, MA, USA: Pergamon.

Vosniadou, S. (1996). Learning environments for representational growth and cognitive flexibility. In S. Vosniadou, E. De Corte, R. Glaser, \& H. Mandl (Eds.), International perspectives on the design of technology supported learning environments (pp. 13-23). Mahwah, NJ, USA: Laurence Erlbaum.

Vygotsky, L. (1979/1925). Consciousness as a problem in the psychology of behavior. Soviet Psychology, 17(4), 3-35. [Or 1997 In R. Rieber \& J. Wollock (Eds.), The collected works of L. S. Vygotsky: Problems of the theory and history of psychology (Vol. 3, pp. 63-79). New York: Plenum.

Walberg, H. J., \& Anderson, G. J. (1968). Classroom climate and individual learning. Journal of Educational Psychology, 59, 414-419. doi:10.1037/h0026490.

Warries, E. (1987). The knowledge base for instructional design. Instructional Science, 16, 105-108.

Wertsch, J. (1991). Voices of the mind: A sociocultural approach to mediated action. Cambridge, MA, USA: Harvard University. 